\title{
Factors Associated with Delayed Diagnosis of Cervical Cancer in Tikur Anbesa Specialized Hospital, Ethiopia, 2019: Cross-Sectional Study
}

This article was published in the following Dove Press journal: Cancer Management and Research

\author{
Shegaw Zeleke ${ }^{\prime}{ }^{\prime}$ \\ Mesfine Anley ${ }^{2}$ \\ Demewoz Kefale' \\ Biresaw Wassihun ${ }^{3}$ \\ 'Department of Nursing, College of \\ Health Sciences, Debre Tabor University, \\ Debre Tabor, Ethiopia; ${ }^{2}$ Department of \\ Oncology Nursing, Tikur Anbesa \\ Specialized Hospital, Addis Ababa, \\ Ethiopia; ${ }^{3}$ Department of Midwifery, \\ College of Health Sciences, Arba Minch \\ University, Arba Minch, Ethiopia
}

Background: Cervical cancer is a preventable and curable disease if detected early enough. But several numbers of women in Ethiopia strive for treatment when the disease has extended to the last stage. Delay in diagnosis is the main reason for cervical cancer mortality in Ethiopia. The main objective of this study was to assess factors associated with delayed diagnoses of cervical cancer in Tikur Anbesa Specialized Hospital, Ethiopia.

Methods: An institution-based cross-sectional study was conducted. Randomly selected 422 cervical cancer patients were interviewed and their medical records were reviewed. Data were entered using EpiData version 3.1 and analyzed using SPSS version 22. Bivariate and multivariate analyses were conducted to examine the association between independent and outcome variables. Results: A total of 410 women participated in the study with a response rate of $97.1 \%$. The mean age of the women was 50 years ( $\mathrm{SD} \pm 11.5$ ). Half of the participants cannot read and write, and $66.3 \%$ of participants' income was $<500$ Ethiopian Birr (approximately 14 USD). Around $86.3 \%$ of the women had delayed diagnosis of cervical cancer. Women who have $<500$ Ethiopian Birr (14 USD) income (adjusted OR=3.79, CI: 1.48, 9.67), have no awareness of cervical cancer disease (adjusted $\mathrm{OR}=1.33$, CI: $1.05,2.71$ ) and have no awareness about cervical cancer screening (adjusted $\mathrm{OR}=1.64, \mathrm{CI}: 1.16,4.07$ ) were more likely for delayed diagnosis of cervical cancer.

Conclusion: Our study reports a high prevalence of delayed diagnosis of women with cervical cancer. A high level of illiteracy, low socioeconomic status, lack of awareness, traditional healers and absence of a routine screening program were accountable for delayed diagnosis of cervical cancer. Regular cervical cancer screening and expansion, raising awareness, increasing access and improving health services for cervical cancer patients should be promoted and advocated to decrease the usual delay in cervical cancer diagnosis. Keywords: cervical cancer, diagnosis, delay, women, Ethiopia

\section{Background}

Cervical cancer is a preventable and curable disease if detected early enough and treated correctly. ${ }^{1}$ Worldwide, cervical cancer accounts for 528,000 new cases every year and almost $70 \%$ of the global burden is in developing countries. ${ }^{2}$ More than $50 \%$ of females affected by cervical cancer are in developing countries and two thirds of them survive for less than 5 years, compared to developed countries. $^{3-5}$ In Africa, high incidences of cervical cancer are reported at rates exceeding 50 per 100,000 population. ${ }^{6}$ In sub-Saharan Africa, cervical cancer is the second commonest cancer morbidity and the leading cause of mortality with
Correspondence: Shegaw Zeleke Department of Nursing, College of Health Sciences, Debre Tabor University, Debre Tabor, Ethiopia

Email shegawzn@gmail.com
Cancer Management and Research 2021:13 579-585 
over 577,000 deaths annually; furthermore, in Eastern Africa it is the number one commonest cancer in women. ${ }^{7}$

In Ethiopia, the age-specific incidence of cervical cancer was higher than the world average for women aged 55 years and above. ${ }^{8}$ Despite the advancement in cancer treatment and diagnosis, cancer still remains one of the most leading causes of death in many countries. One of the main reasons for this is the delay in diagnosis or initiation of treatment at an advanced stage. ${ }^{9,10}$ A delay in diagnosis can occur for many reasons such as: when an individual does not attend for screening; when the screening service does not diagnose the cancer, when an incidental finding is not appropriately acted upon; if an individual does not recognize a symptom of cancer; an individual with symptoms does not seek healthcare advice; or healthcare providers (HCPs) or the health system fails to detect cancer. ${ }^{11}$ In sub-Saharan Africa countries, a lack of effective screening and treatment policies, strategies and programs is accountable for high cervical cancer prevalence and mortality. ${ }^{7}$ In Uganda, cervical cancer diagnosis delays were related to the patient and with more than $65 \%$ of patients developing advanced stage cancer due to lack of money. Additionally, about $71.8 \%$ of the patients presented with advanced stage diagnosis with delays related to healthcare-related factors. ${ }^{12}$ In Morocco, the reason for patient-related delay was minimal knowledge of cervical cancer symptoms, accessing information from nonmedical personnel, fear of cancer death, lack of awareness and poverty. ${ }^{13}$ In Ethiopia, almost 7,095 women are annually diagnosed with cervical cancer and about 4,732 die annually, and also cervical cancer is the number one cancer in Ethiopia. ${ }^{8,14}$ In Ethiopia, there is evidence for the death of cervical cancer patients associated with a delay in diagnosis. So, these facts prompted the researchers to embark on the assessment of factors associated with delayed diagnosis of cervical cancer in Tikur Anbesa Specialized Hospital Ethiopia.

\section{Methods}

\section{Study Setting and Design}

The study was conducted at Tikur Anbesa Specialized Hospital which is located in Addis Ababa Ethiopia. It is the largest oncology center throughout Ethiopia. This hospital serves a total of 99.4 million people. ${ }^{15}$ Tikur Anbesa Specialized Hospital oncology center serves an estimated number of 80,000 new patients per year. An institutionalbased cross-sectional study design was used.

\section{Population and Sample}

All cervical cancer patients with age 18 years and above who were attending Tikur Anbesa Specialized Hospital as new and follow up were included in the study. The sample size was determined using a single population proportion formula and the following assumptions were made to get the maximum sample size. The prevalence of delayed diagnosis of cervical cancer was $50 \%(p=0.5)$, level of significance was $5 \%(\alpha=0.05), 95 \%$ confidence level $\left(\mathrm{Z} \frac{\mathrm{a}}{2}=1.96\right)$ and absolute precision or margin of error was $5 \%(\mathrm{~d}=0.05)$. By adding a $10 \%$ non-response rate the total sample size was 422 .

\section{Sampling Procedure and Study Variables}

A simple random number table sampling method was used to select cervical cancer patients and then cervical cancer patients were interviewed and their medical records were reviewed. The outcome variable was delayed diagnosis of cervical cancer. Based on the International Federation of Gynecology and Obstetrics (FIGO), early diagnosis of cervical cancer patients was defined as stage IA1, IA2, IB1, IB2, IIA1, IIA2 and IIB cervical cancer and delayed diagnosis of cervical cancer patients was defined as stage IIIA, IIIB, IVA and IVB cervical cancer. ${ }^{16}$

\section{Data Collection, Tools and Procedures}

The data were collected using a structured intervieweradministered questionnaire adapted from an in-depth literature review. ${ }^{9,17}$ The questionnaire had two sections: 1) socio-demographic information of respondents; and 2) delay in diagnosis-related factors. The questionnaire was prepared in English and translated to Amharic language by a second person and lastly back-translated to English language by a third person to see the consistency of questions. The questionnaire was checked thoroughly for objectivity and variable assessment before it was distributed to the data collectors. Half-day training was given to the data collectors and the supervisors on the study protocol including study objectives, relevance of the study and confidentiality of information, respondent's rights and informed consent. Two supervisors who were nurses holding a bachelor science degree and four data collectors who were nurses holding a diploma were recruited. All cervical cancer patients who fulfill the inclusion criteria were consented and interviewed and their medical record was reviewed. The investigators and the supervisors made frequent checks on the data collection process to ensure 
completeness and consistency of the gathered information. Appropriate research ethical clearance was obtained from the ethical review committee of Addis Ababa University. This study was conducted in accordance with the Declaration of Helsinki: each study participant was well informed about the aim of the study, benefits and risks; informed written consent was secured from study participants; study participants' confidentiality was maintained; no personal identifiers were used in the data collection questionnaire, and codes were used in place of them; the recorded data were not accessed by a third person, except the researcher; and data sharing will be enacted based on the consent and permission of research participants.

\section{Data Processing and Analysis}

Data were entered into the computer using EpiData version 3.1 and transported to Statistical Package for Social Sciences (SPSS) version 22.0 for analysis. Descriptive and inferential statistics were analyzed and presented. Initially, bivariate logistic regression was carried out to see the association of each independent variable with the outcome variable. Thereafter, to see the relationship of delayed diagnosis and socio-demographic and other variables, multivariable logistic regression was used. Variables with $p$-value $\leq 0.2$ in the bivariate logistic regression were used in the multiple logistic regression analysis. $p$--value $\leq 0.05$ and $95 \%$ confidence level was considered as statistical significance.

\section{Results}

\section{Socio-Demographic Characteristics of the Study Participants}

A total of 410 women participated in the study with a response rate of $97.1 \%$. The mean age of women was 50 years $(\mathrm{SD} \pm 11.5)$ with the range from $18-80$ years. About 29.8\% (122) and 30.2\% (124) of the respondents were in the age groups of 35-44 and 45-54 years respectively. Regarding the region, $34.4 \%$ (141) and $31.2 \%$ (128) were from Oromia and Amhara respectively. Among the participants, $67.1 \%$ (275) of the respondents were Orthodox religion followers. In this study, half (205) of the respondents cannot read and write and $69.5 \%$ (285) of respondents' occupational status was farmer. Almost three quarters of the respondents (304) came from a radius greater than 100 kilometers to Tikur Anbesa Specialized Hospital oncology center. Two thirds of the respondents' (272) income status was below 500 birr (approximately 14 USD) per month (Table 1).
Table I Socio-Demographic Characteristics of Cervical Cancer Patients Attending at Tikur Anbesa Specialized Hospital Oncology Center Addis Ababa, Ethiopia $(n=410)$

\begin{tabular}{|c|c|c|}
\hline Variables & Frequency & Percent (\%) \\
\hline \multicolumn{3}{|l|}{ Residency } \\
\hline Urban & 223 & 54.4 \\
\hline Rural & 187 & 45.6 \\
\hline \multicolumn{3}{|l|}{ Region } \\
\hline Amhara & 128 & 31.2 \\
\hline Oromia & $|4|$ & 34.4 \\
\hline Addis Ababa & 75 & 18.3 \\
\hline SNNP & 35 & 8.5 \\
\hline Tigre & 18 & 4.4 \\
\hline Others* & 12 & 2.9 \\
\hline \multicolumn{3}{|l|}{ Religion } \\
\hline Orthodox & 275 & 67.1 \\
\hline Protestant & 60 & 14.6 \\
\hline Catholic & 2 & 0.5 \\
\hline Muslim & 73 & 17.8 \\
\hline \multicolumn{3}{|l|}{ Marital status } \\
\hline Married & 285 & 69.5 \\
\hline Single & II & 2.7 \\
\hline Divorced & 36 & 8.8 \\
\hline Widowed & 78 & 19.0 \\
\hline \multicolumn{3}{|l|}{ Educational status } \\
\hline Cannot read and write & 205 & 50.0 \\
\hline Informal education & 74 & 18.0 \\
\hline Primary & 75 & 18.3 \\
\hline Secondary & 32 & 7.8 \\
\hline College & 24 & 5.9 \\
\hline \multicolumn{3}{|l|}{ Occupational status } \\
\hline Farmer & 182 & 44.4 \\
\hline Governmental & 27 & 6.6 \\
\hline Private & 54 & 13.2 \\
\hline Unemployed & 147 & 35.9 \\
\hline \multicolumn{3}{|l|}{ Distance to oncology center } \\
\hline$<100 \mathrm{~km}$ & 106 & 25.9 \\
\hline$>100 \mathrm{~km}$ & 304 & 74.1 \\
\hline
\end{tabular}

Note: *Gambela, Somalia, Harare, Afar and Benshangule.

\section{Prevalence of Delayed Diagnosis to Cervical Cancer and Related Factors}

In this study, $86.3 \%(n=354)$ of patients had advanced stage (IIIA-IVB) or delayed diagnosis during confirmation of their cervical cancer and $72.0 \%$ (295) of the participants received radiotherapy services. The median days of stay at home was 120 days with their symptoms. Of the first noticed participant symptoms, 
$36.8 \%$ (151) was foul smelling vaginal discharge and $32.4 \%$ (133) was vaginal bleeding. Regarding respondent awareness, $83.4 \%$ (342) had never heard about cervical cancer, $91.0 \%$ (373) had a lack of information about cervical cancer screening and, almost all, 96.3\% (395) of respondents had never heard about the causes of cervical cancer (Table 2).

Table 2 Factors Related to Delayed Diagnosis of Cervical Cancer Patient Attending at Tikur Anbesa Specialized Hospital Oncology Center Addis Ababa, Ethiopia $(n=410)$

\begin{tabular}{|c|c|c|}
\hline Variables & Frequency & $\begin{array}{l}\text { Percent } \\
\text { (\%) }\end{array}$ \\
\hline \multicolumn{3}{|l|}{ Awareness of cervical cancer disease } \\
\hline Yes & 68 & 16.6 \\
\hline No & 342 & 83.4 \\
\hline \multicolumn{3}{|l|}{ Awareness of cervical cancer screening } \\
\hline Yes & 37 & 9.0 \\
\hline No & 373 & 91.0 \\
\hline \multicolumn{3}{|l|}{ Family history of cancer } \\
\hline Yes & 24 & 5.9 \\
\hline No & 386 & 94.1 \\
\hline \multicolumn{3}{|l|}{$\begin{array}{l}\text { Awareness of the causes of cervical } \\
\text { cancer }\end{array}$} \\
\hline Yes & 15 & 3.7 \\
\hline No & 395 & 96.3 \\
\hline \multicolumn{3}{|l|}{ Awareness of cervical cancer staging } \\
\hline Yes & 85 & 20.7 \\
\hline No & 325 & 79.3 \\
\hline \multicolumn{3}{|l|}{ Unfolds their symptoms to } \\
\hline Husband & 67 & 16.3 \\
\hline Friend & 10 & 2.4 \\
\hline Family & 138 & 33.7 \\
\hline Health workers & 194 & 47.3 \\
\hline Religious father & I & 00.2 \\
\hline \multicolumn{3}{|l|}{ Referral pathway to diagnoses center } \\
\hline From governmental institutions & 245 & 59.8 \\
\hline From private institutions & 129 & 31.5 \\
\hline Both & 36 & 8.8 \\
\hline \multicolumn{3}{|l|}{$\begin{array}{l}\text { Cervical cancer patient first noticed } \\
\text { symptoms }\end{array}$} \\
\hline Bleeding after sexual intercourse & 67 & 16.3 \\
\hline Foul smelling vaginal discharge & 151 & 36.8 \\
\hline Lower abdominal and back pain & 55 & 13.4 \\
\hline Weight loss & 4 & I \\
\hline Vaginal bleeding & 133 & 32.4 \\
\hline
\end{tabular}

\section{Factors Associated with Delayed Diagnosis Among Cervical Cancer Patients}

Binary logistic regression was performed to assess the association of each independent variable with delayed diagnosis of cervical cancer. Factors which had a $p$-value of $\leq 0.2$ were included in the multivariable regression model (Table 3).

\section{Discussion}

In the current study, six out of seven cases of cervical cancer in Ethiopia were found to have delayed diagnosis. Delayed diagnosis of cervical cancer increases the proportion of cervical cancer cases in an advanced stage and also leads to treatment complications and may not cure. Thus, delay in diagnosis of cervical cancer patients may impact on prognosis and quality of life. ${ }^{18}$ Our study participants' mean age was $50(\mathrm{SD} \pm 11.5)$. This result is consistent with research conducted in Morocco, Iran and Nepal where the mean age was 52.4 years ( $\mathrm{SD} \pm 11.48), 48.3(\mathrm{SD} \pm 12.01)$ and 52.72 years ( $\mathrm{SD} \pm 10.63$ ) respectively., ${ }^{3,17}$ The prevalence of delayed diagnosis of cervical cancer in women is $86.3 \%$. In contrast, the prevalence of delayed diagnosis of cervical cancer in the UK and Malawi was $38 \%$ and $77 \%$ respectively. ${ }^{3,10}$ This discrepancy might be due to ignoring the mild gynecological symptoms, shortage of diagnostic centers, high level of illiteracy, low socioeconomic status, lack of awareness about cervical cancer disease and screening, absence of a routine screening program and wasting time in traditional healers. Therefore, the health professionals shall work on awareness creation activities toward cervical cancer disease and expanding the cervical cancer screening and immunization service in Ethiopia. The median days of delayed diagnosis was 120 days. This median days of delay was found to be higher than a study conducted in Nepal which had a median delay of 40 days. ${ }^{19}$ This inconsistency might be due to the influence of patient's characteristics such as high level of illiteracy, poor health awareness, poor economic condition, problematic health-seeking behavior, as well as dependency on traditional practices. This problem needs to be solved with the inter-collaboration activities of religious leaders, health, education and agriculture sectors in order to minimize traditional practice, raising the awareness of the women, minimizing illiteracy level and improving their economic status. These can reduce the delay in diagnosis of cervical cancer. 
Table 3 Demographic and Cancer-Related Factors in Women with Delayed Diagnosis of Cervical Cancer in Tikur Anbesa Specialized Hospital Oncology Center Addis Ababa, Ethiopia, 2019

\begin{tabular}{|c|c|c|c|c|}
\hline \multirow[t]{3}{*}{ Categorical Variables } & \multicolumn{2}{|l|}{ Diagnosis } & \multicolumn{2}{|l|}{ OR $(95 \% \mathrm{Cl})$} \\
\hline & \multirow{2}{*}{\begin{tabular}{|l} 
Early \\
$\mathbf{N}(\%)$
\end{tabular}} & \multirow{2}{*}{$\begin{array}{l}\text { Delayed } \\
\mathbf{N}(\%)\end{array}$} & \multirow[t]{2}{*}{ Crude } & \multirow[t]{2}{*}{ Adjusted } \\
\hline & & & & \\
\hline \multicolumn{5}{|l|}{ Residency } \\
\hline Urban & $85(38.1)$ & $38(61.9)$ & I & I \\
\hline Rural & $39(20.9)$ & $148(79.1)$ & $2.33(1.49,3.64)$ & $1.18(1.05,2.45)$ \\
\hline \multicolumn{5}{|l|}{ Occupation } \\
\hline Farmer & $33(18.0)$ & $150(82.0)$ & 1 & I \\
\hline Governmental & II (39.3) & $17(60.7)$ & $0.34(0.14,0.79)$ & $\mathrm{I} .08(0.3 \mathrm{I}, 3.75)$ \\
\hline Private & $20(38.5)$ & $32(61.5)$ & $0.35(0.18,0.69)$ & $0.53(0.22,1.3 \mathrm{I})$ \\
\hline Unemployed & $60(40.8)$ & $87(59.2)$ & $0.3 \mathrm{I}(0.19,0.52)$ & $0.45(0.21,0.96)$ \\
\hline \multicolumn{5}{|l|}{ Income } \\
\hline$<500$ birr & $80(29.2)$ & $194(70.8)$ & $3.03(1.49,6.14)$ & $3.79(1.48,9.67)$ \\
\hline $500-1000$ birr & $24(24.0)$ & $76(76.0)$ & $3.95(1.77,8.82)$ & $4.14(1.50,11.39)$ \\
\hline$>1000$ birr & $20(55.6)$ & $16(44.4)$ & 1 & I \\
\hline \multicolumn{5}{|l|}{ Religion } \\
\hline Orthodox & $78(28.4)$ & $197(71.6)$ & $2.08(1.22,3.54)$ & $2.52(1.40,4.56)$ \\
\hline Protestant & II (I8.3) & $49(81.7)$ & $3.67(1.65,8.17)$ & $3.85(1.60,9.29)$ \\
\hline Muslim & $35(46.7)$ & $40(53.3)$ & 1 & I \\
\hline \multicolumn{5}{|l|}{ Awareness about cervical cancer disease } \\
\hline Yes & $28(42.4)$ & $38(57.6)$ & 1 & 1 \\
\hline No & $96(27.9)$ & $248(72.1)$ & $1.90(1.11,3.27)$ & $1.33(1.05,2.71)$ \\
\hline \multicolumn{5}{|l|}{ Awareness about cervical cancer screening } \\
\hline Yes & $17(45.9)$ & $20(54.1)$ & 1 & 1 \\
\hline No & $107(28.7)$ & $266(71.3)$ & $2.11(1.06,4.18)$ & $1.64(1.16,4.07)$ \\
\hline \multicolumn{5}{|l|}{ Reasons for delay } \\
\hline Accept as cancer cannot heal & $3(16.7)$ & $15(83.3)$ & $6.66(1.47,30.21)$ & $7.28(1.38,38.34)$ \\
\hline Go to traditional healers & $3(15.8)$ & $16(84.2)$ & $7.11(1.57,32.05)$ & $9.10(1.45,56.86)$ \\
\hline Difficulty of decision & $13(19.4)$ & $54(80.6)$ & $5.53(1.92,15.91)$ & $6.20(1.91,20.12)$ \\
\hline Can be healed by itself & $81(34.6)$ & $153(65.4)$ & $2.51(1.01,6.22)$ & $2.90(1.04,8.03)$ \\
\hline Given priority for other diseases & $10(34.5)$ & $19(65.5)$ & $2.53(0.79,8.03)$ & $2.21(0.61,8.00)$ \\
\hline Embarrassment & $2(I I . I)$ & $16(88.9)$ & $10.6(1.93,58.69)$ & $10.0(1.66,60.19)$ \\
\hline Unawareness of cervical cancer health service access & $12(48.0)$ & $13(52.0)$ & 1 & I \\
\hline
\end{tabular}

Abbreviations: $\mathrm{N}$, number; \%, percent; OR, odds ratio; $\mathrm{Cl}$, confidence interval.

In regards to awareness, approximately $83.4 \%$ of women lacked information about cervical cancer disease. A study conducted in Morocco reported $60.3 \%$ of cervical cancer patients had awareness about cervical cancer diseases; this difference might be due to lack of health information dissemination in this study context and a higher illiteracy rate in Ethiopia as compared to Morocco. ${ }^{12}$ In this study, low socioeconomic status was independently associated with patient's delayed diagnosis. Similarly, studies conducted in China, Uganda and Morocco showed that low socioeconomic status was found as a risk factor for patient delayed diagnosis. ${ }^{4,12,20}$ Cervical cancer women visiting a traditional healer were the most identified analysis for delayed diagnosis. A similar study revealed in Uganda that traditional healers were a predictor for delayed diagnosis in cervical cancer. ${ }^{4}$ In this study, during medical record review over $51.7 \%$ had an advanced stage (IIIA-IVB). Because, women usually tend to ignore the mild to moderate gynecological symptoms such as vaginal discharge considering it as a general problem and do not discuss their problem with others until it becomes warning symptoms such as vaginal bleeding 
and severe pelvic pain. This result is similar to research done in Morocco, China and Kenya with 55.4\%, 66.7\% and $55.8 \%$ respectively. ${ }^{4,12,21}$ The advanced stage at presentation might be due to detection of the symptom at later stages or lack of awareness for early screening. Similarly, on initiation to treatment over $70 \%$ of the participants had an advanced stage (IIIA-IVB) of cervical cancer. This finding is also parallel with Uganda's study, which reported $71.8 \%$ of the participants were at an advanced stage. In contrast, a study conducted in Malaysia revealed $26 \%$ of patients had advanced stage of cervical cancer on initiation of treatment. This discrepancy might be due to lack of consistent screening service, training program for health staff, lack of treatment centers and public awareness.

\section{Conclusion}

The prevalence of delayed diagnosis of cervical cancer was high and also the median time of delay was long. Lack of awareness about cervical cancer disease and screening, practice in traditional healers and low income level are the most responsible factors for high prevalence of delayed diagnosis of cervical cancer in Ethiopia. Health messaging should focus to raise women's awareness, how to self-identify and on symptoms related to cervical cancer. Despite a huge element of cost, availing vaccine, advanced diagnostic procedures and access to chemo-radiation treatment in each region are also paramount. Our study calls for a multi-sectored approach in addressing cervical cancer conditions in Ethiopia, that requires huge stakeholder involvement including the Ministry of Health (policy-makers), agriculture sector, educational and training institutions, hospitals, communities, families and individuals.

\section{Abbreviations}

HCPs, healthcare providers; BSC, Bachelor of Sciences; SD, standard deviation; SPSS, Statistical Package for Social Sciences; AOR, adjusted odds ratio; CI, confidence interval; AAU, Addis Ababa University.

\section{Ethics Approval and Consent to Participate}

The research proposal was approved by Addis Ababa University research ethical committee. This study was conducted in accordance with the Declaration of Helsinki: each study participant was well informed about the aim of the study, benefits, and risks; informed written consent was secured from study participants; study participants' confidentiality was maintained; no personal identifiers were used in the data collection questionnaire, and codes were used in place of them.

\section{Acknowledgments}

The authors are grateful to the data collectors and study participants.

\section{Author Contributions}

All authors made substantial contributions to conception and design, acquisition of data, or analysis and interpretation of data; took part in drafting the article and revising it critically; agreed to submit to the current journal; gave final approval of the version to be published; and agree to be accountable for all aspects of the work.

\section{Funding}

There is no funding to report.

\section{Disclosure}

The authors declare that they have no conflicts of interest for this work.

\section{References}

1. Bouley AJ, Biggs HM, Stoddard RA, et al. Brucellosis among hospitalized febrile patients in northern Tanzania. Am J Trop Med Hyg. 2012;87(6):1105-1111. doi:10.4269/ajtmh.2012.12-0327

2. Organization WH. WHO guidance note: comprehensive cervical cancer prevention and control: a healthier future for girls and women. 2013.

3. Chadza E, Chirwa E, Maluwa A, et al. Factors that contribute to delay in seeking cervical cancer diagnosis and treatment among women in Malawi. 2012.

4. Ma J, Zhu Q, Han S, et al. Effect of socio-economic factors on delayed access to health care among Chinese cervical cancer patients with late rectal complications after radiotherapy. Gynecol Oncol. 2012;124 (3):395-398. doi:10.1016/j.ygyno.2011.11.040

5. Jemal A, Center MM, DeSantis C, et al. Global patterns of cancer incidence and mortality rates and trends. Cancer Epidemiol Biomarkers Prev. 2010;19(8):1893-1907. doi:10.1158/1055-9965.EPI-10-0437

6. Ferlay J, Soerjomataram I, Dikshit R, et al. Cancer incidence and mortality worldwide: sources, methods and major patterns in GLOBOCAN 2012. Int $J$ Cancer. 2015;136(5):E359-E386. doi:10.1002/ijc.29210

7. WHO. Human Papillomavirus and related cancers in Ethiopia: summary report 2010. CFTOKEN. 2010.

8. Alok Kumar D, Sada Nand D, Suryanarayana D, et al. An epidemiological study on delay in treatment initiation of cancer patients. Health. 2012;2012.

9. Assefa AA, Astawesegn FH, Eshetu B. Cervical cancer screening service utilization and associated factors among HIV positive women attending adult ART clinic in public health facilities, Hawassa town, Ethiopia: a cross-sectional study. BMC Health Serv Res. 2019;19 (1):847. doi:10.1186/s12913-019-4718-5 
10. Agency NPS. Delayed diagnosis of cancer: thematic review. NPSA London; 2010.

11. Behnamfar F, Azadehrah M. Factors associated with delayed diagnosis of cervical cancer in iran-a survey in isfahan city. Asian Pac $J$ Cancer Prev. 2015;16(2):635-639. doi:10.7314/APJCP.2015.1 6.2 .635

12. Berraho M, Obtel M, Bendahhou K, et al. Sociodemographic factors and delay in the diagnosis of cervical cancer in Morocco. Pan Afr Med J. 2012;12(1).

13. Hailemariyam A. An evaluation of effectiveness of ethio-morphin to control moderate severe pain of cancer patient TASH RT. 2013.

14. Macleod U, Mitchell ED, Burgess C, Macdonald S, Ramirez AJ. Risk factors for delayed presentation and referral of symptomatic cancer: evidence for common cancers. PMCID. 2009;10(1038):92-101.

15. Asmamaw DK. A critical review of the water balance and agronomic effects of conservation tillage under rain-fed agriculture in Ethiopia. Land Degrad Dev. 2017;28(3):843-855. doi:10.1002/ldr.2587

16. Mikuta JJ. International federation of gynecology and obstetrics staging of endometrial cancer 1988. Cancer. 1993;71(S4):1460-1463. doi:10.1002/cncr.2820710409
17. Sullivan R, Badwe RA, Rath GK, et al. Cancer research in India: national priorities, global results. Lancet Oncol. 2014;15(6):e213e222. doi:10.1016/S1470-2045(14)70109-3

18. Thomson C, Forman D. Cancer survival in England and the influence of early diagnosis: what can we learn from recent EUROCARE results? $B r \quad J$ Cancer. 2009;101(2):S102-S109. doi:10.1038/sj. bjc. 6605399

19. Gyenwali D, Pariyar J, Onta SR. Factors associated with late diagnosis of cervical cancer in Nepal. Asian Pac J Cancer Prev. 2013;14 (7):4373-4377. doi:10.7314/APJCP.2013.14.7.4373

20. Matthey F, Parker A, Rule S, et al. Facilities for the treatment of adults with haematological malignancies-'Levels of Care': BCSH Haemato-oncology task force 2009. Hematology. 2010;15(2):63-69. doi:10.1179/102453309X12583347113492

21. Barber M, Jack W, Dixon J. Diagnostic delay in breast cancer. $\mathrm{Br}$ J Surg. 2004;91(1):49-53. doi:10.1002/bjs.4436

\section{Publish your work in this journal}

Cancer Management and Research is an international, peer-reviewed open access journal focusing on cancer research and the optimal use of preventative and integrated treatment interventions to achieve improved outcomes, enhanced survival and quality of life for the cancer patient.
The manuscript management system is completely online and includes a very quick and fair peer-review system, which is all easy to use. Visit http://www.dovepress.com/testimonials.php to read real quotes from published authors. 